\title{
DE ARRAIAL A BAIRRO INDUSTRIAL - O QUE O NAVEGANTES AINDA TEM?
}

\author{
Luciana de Mello ${ }^{1}$ \\ Ana Luiza Carvalho da Rocha (orientação)

\begin{abstract}
A densidade, os valores da terra, os aluguéis, a acessibilidade, a salubridade, o prestígio, considerações estéticas, a ausência de inconvenientes tais como barulho, fumaça e sujeira, determinam a atratividade de várias áreas da cidade como locais para o estabelecimento de diferentes camadas da população.

(Louis Wirth, "O urbanismo como modo de vida")
\end{abstract}

\section{Introdução}

A trajetória das formas de vida urbana no bairro Navegantes, em Porto Alegre, considerando-se os diversos gestos de ocupação deste território, é aqui pensada a partir dos ecos do seu passado, trazidos até os dias de hoje, por meio de imagens literárias, visuais e sonoras, antigas e recentes, desta área da cidade. Estas imagens foram acessadas no acervo do Banco de Imagens e Efeitos Visuais e aliadas a investidas de trabalho de campo no bairro Navegantes, pela via de uma etnografia de rua. Em especial, foram escolhidas para a pesquisa determinadas áreas deste bairro marcadas, em seu desenho atual, pelo registro de fragmentos

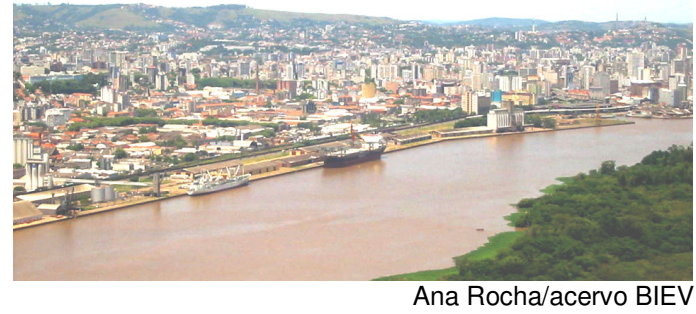
de distintas temporalidades e que, por esta razão, permitiriam a este estudo aprofundar uma reflexão sobre as transformações nas formas de vida social na cidade de Porto Alegre.

Hoje, diferentemente do passado, o bairro Navegantes encontra-se escondido, de um lado, por uma série de modificações ocorrida na orla do Lago Guaíba - aterro, trilhos de trem, avenida Castelo Branco - tendo perdido sua vista para as inúmeras ilhas que ornamentam o estuário do Lago Guaíba. Do outro lado, são os bairros adjacentes - Centro, Independência, São Geraldo, Floresta e São João aqueles que condicionam os limites.

\footnotetext{
${ }^{1}$ Bolsista FAPERGS no projeto de pesquisa "Banco de Imagens e Efeitos Visuais: a criação de um museu virtual" sob a coordenação da Prof ${ }^{\mathrm{a}}$. Dr ${ }^{\mathrm{a}}$. Ana Luiza Carvalho da Rocha, dentro do projeto "Estudo de Itinerários Urbanos, Memória Coletiva e Formas de Sociabilidade no Meio Urbano Contemporâneo" com coordenação geral da Prof ${ }^{\mathrm{a}}$. Dr ${ }^{\mathrm{a}}$. Cornelia Eckert, Programa de Pós Graduação em Antropologia Social, Instituto de Filosofia e Ciências Humanas, UFRGS.
} 


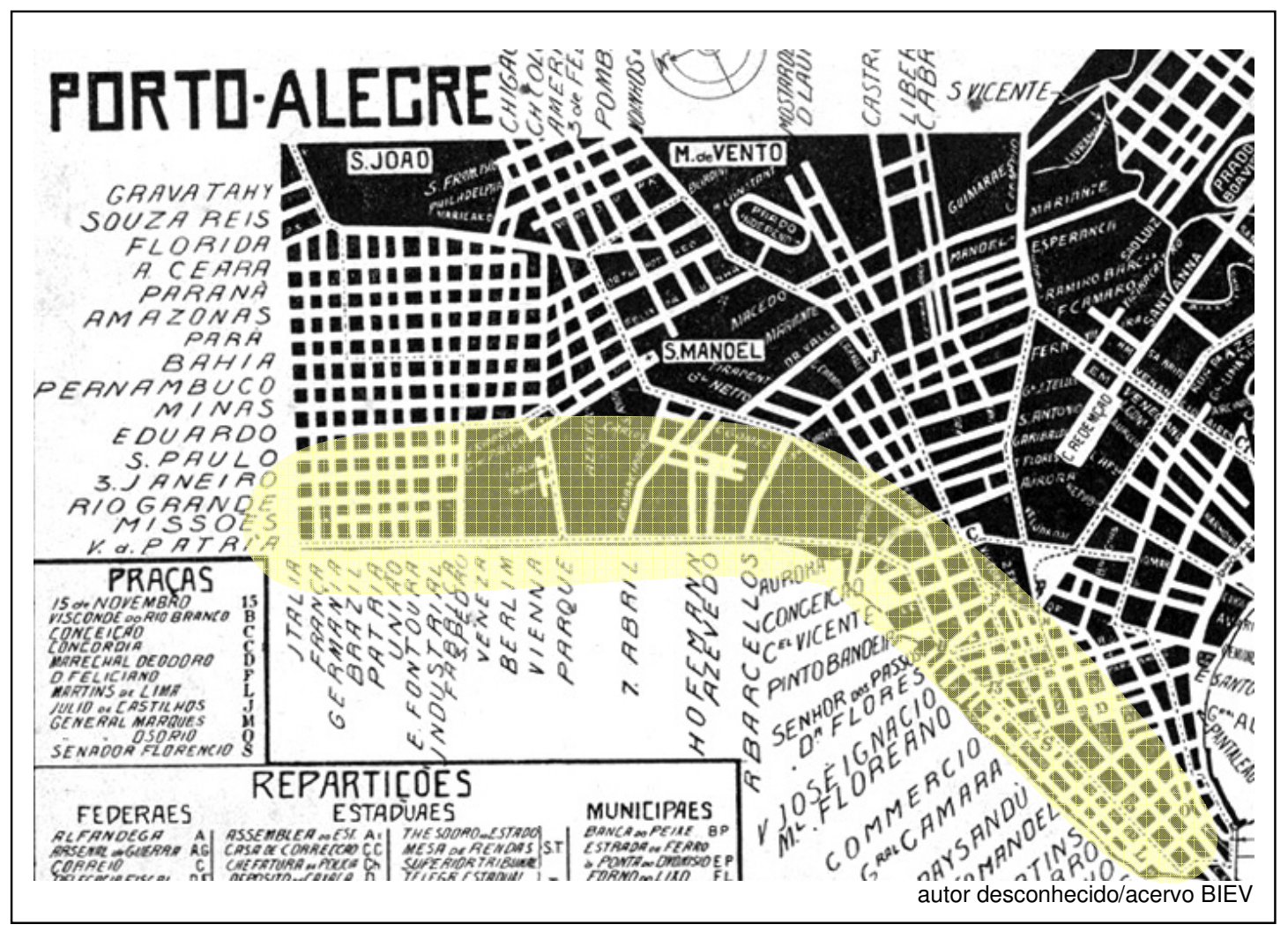

Sendo o Navegantes um bairro de menos prestígio social que os anteriores, e que faz fronteira com eles, a pergunta que motivou a entrada no trabalho de campo neste território da região norte de Porto Alegre foi a seguinte: ainda que não tenha se constituído como bairro pelo planejamento municipal, como nasceu esta denominação "bairro Navegantes" na memória coletiva da cidade? Como esse espaço da cidade foi se constituindo no que é hoje? E o que é hoje esse lugar?

$\mathrm{Na}$ tentativa de buscar uma resposta para este questionamento é que foi realizada uma etnografia do espaço compreendido entre as primeiras quadras do atual "bairro Navegantes', em Porto Alegre, RS, junto à orla do Guaíba, mais precisamente da Av. Voluntários da Pátria, e algumas ruas transversais a esta até a Av. Sertório, e as ruas paralelas a ela, limitando-o ao território compreendido entre as avenidas Farrapos e Presidente Roosevelt.

A inspiração para o estudo foram os comentários de Robert Park $^{2}$ a propósito da complexa trama de lugares a partir dos quais as grandes metrópoles podem ser pesquisadas, onde o autor afirma que a cidade possui uma organização moral, bem como uma organização física, e estas duas interagem mutuamente de modos característicos para se moldarem e se modificarem uma a outra. Tendo como guia esta afirmação pontual é que

\footnotetext{
${ }^{2}$ PARK, Robert Ezra. A cidade: sugestões para a investigação do comportamento humano no meio urbano. In: Velho, Otávio Guilherme. O fenômeno urbano. Rio de Janeiro: Ed. Zahar, 1976. p.29.
} 
as incursões em campo se iniciaram no espaço do bairro Navegantes, numa tentativa enquadrar no tempo as pistas das antigas organizações morais que conformaram a organização física deste território na vida urbana porto-alegrense.

\section{Os desafios de um trabalho com a memória}

No cumprimento de uma rotina de observação participante na vida cotidiana do território eleito para o trabalho de campo, foram escolhidos diferentes horários e dias da semana, buscando apreender os diversos usos ali praticados por seus habitantes. Completando estas incursões no tempo presente do bairro, foram realizadas incursões no bairro Navegantes de outros tempos, a partir da leitura de jornais antigos, de relatos de cronistas e da análise de

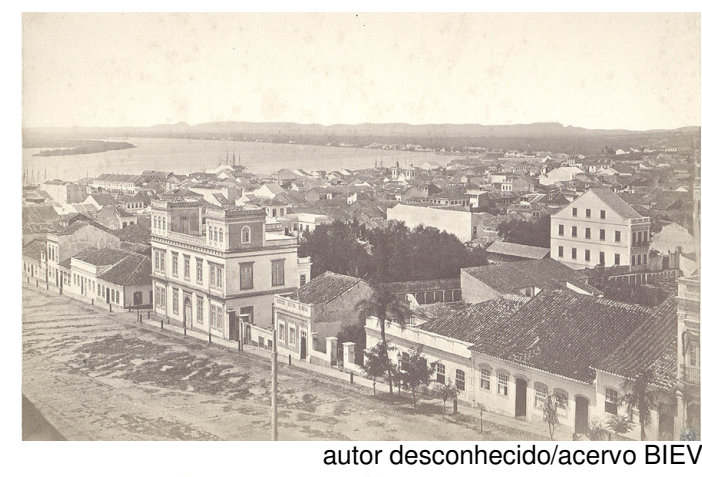

imagens de acervo pesquisadas nos museus de Porto Alegre e nas coleções etnográficas do Banco de Imagens e Efeitos Visuais.

O processo de trabalho de campo e as pesquisas em acervos foram acompanhados da produção escrita de um diário de campo. Além

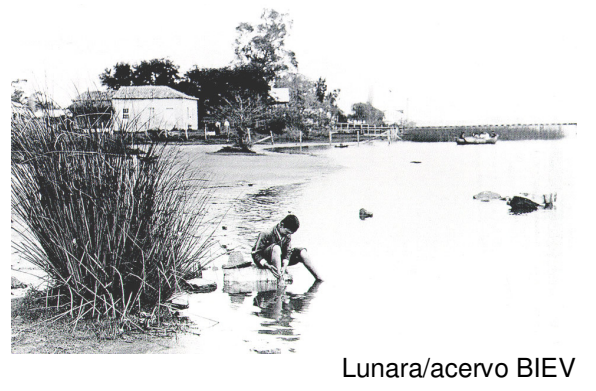
disto, as situações de campo propiciaram circunstancialmente o registro de uma etnografia sonora e visual de certos lugares e territórios da área investigada, numa tentativa de se capturar o dia-a-dia no bairro, as transformações locais e a sua contextualização do Navegantes perante as dinâmicas espaciais da cidade de Porto Alegre, em suas distintas temporalidades. Do ponto de vista da realização de uma etnografia sonora da paisagem local, a idéia era ampliar o estudo da ambiência urbana da região adotada para pesquisa, apoiando-se nos estudos da poética do espaço de Gaston Bachelard ${ }^{3}$ e do sentido acontecimento sonoro em Michel Chion ${ }^{4}$.

O universo desta pesquisa abrange, portanto, espacial e temporalmente, o que era denominada a região do Caminho Novo, adjacente a norte do centro da cidade, antigo Arraial dos Navegantes. Mais tarde este local se constituiria em bairro fabril, predominantemente teuto-brasileiro, a partir do intenso comércio dos produtos vindos

\footnotetext{
${ }^{3}$ BACHELARD, Gaston. 1884-1962. A poética do espaço. São Paulo: Martins Fontes, 1993.

${ }^{4}$ CHION, Michel. Le son. Paris: Natan, 1998.
} 
principalmente das colônias alemãs, resultando no surgimento de uma série de indústrias e residências de trabalhadores e familiares que ali se estabeleceram em torno destas atividades. Em sua ocupação mais recente, o bairro Navegantes apresenta-se com algumas características de distintas épocas e com modificações em seus usos, o que sugere que grande parte dos fragmentos presentes em elementos do espaço, como infra-estrutura e firmas, na atualidade, tiveram adaptações em seus usos, decorrentes do contexto do bairro em relação à cidade, e vice-versa.

Um panorama da cidade e do bairro pode ser

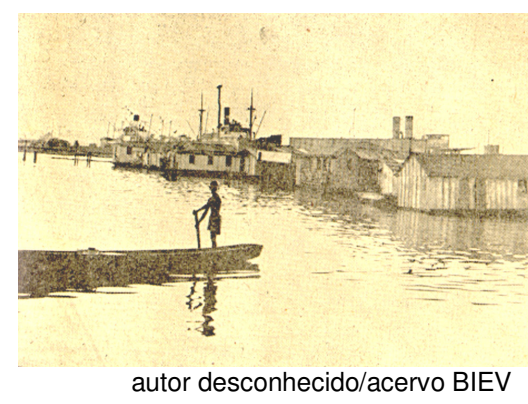
traçado cruzando alguns aspectos da história e da geografia de Porto Alegre, tendo como ponto de apoio a memória coletiva que guarda Navegantes na vida urbana portoalegrense. Adota-se aqui no caso a perspectiva de uma etnografia da duração tal qual concebida por Eckert e Rocha. Segundo as autoras, considerando-se a matéria lacunar do tempo, os trabalhos da memória contemplam o ato simbólico de ordenar tais descontinuidades e preencher suas lacunas; um processo que acaba por constituir a memória como um espaço fantástico de amarração presente-passado, ${ }^{6}$ Neste sentido, o contato com as imagens de acervo do bairro Navegantes, presentes nas obras de historiadores, cronistas e fotógrafos de época são referenciais para este trabalho pois apontam para os jogos da memória que fizeram deste lugar um espaço importante para a compreensão da atual feição urbana e industrial de Porto Alegre. Foram utilizados, para tanto, trabalhos de Francisco Riopardense de Macedo, Sérgio da Costa Franco, Sandra Pesavento, Marino Lobello, Antônio Álvares Pereira Coruja, Walter Spalding, Eloy Terra, Alexandre Fortes e Heloisa Reichel .

\section{Remontando o tempo de formação do bairro}

Na Porto Alegre do início do século XIX, de um lado, a Voluntários da Pátria foi aberta, como Caminho Novo, para ser uma rua que margeasse o Guaíba. Por outro lado, já em 1830 era freqüente a movimentação de caixeiros-viajantes pelos caminhos próximos a foz do rio Gravataí, que ligavam a cidade com outros municípios.

\footnotetext{
${ }^{5}$ SANTOS, Milton. Espaço e método. São Paulo: Nobel, 1985. p.5.

${ }^{6}$ ECKERT, Cornelia; ROCHA, Ana Luiza Carvalho da. A memória como espaço fantástico. Iluminuras: Série do Banco de Imagens e Efeitos Visuais, número 02. Porto Alegre: BIEV, PPGAS/UFRGS, 2000.
} 
O arraial dos Navegantes constituía-se de chácaras e sítios, em até meados do século XIX. A abertura do Caminho Novo se deu ainda de 1805 a 1810, pelo Governador Paulo José da Silva Gama, idealizando-a como uma elegante alameda à beira do Guaíba com árvores em ambos os lados. Estendia-se originalmente da Praça Parobé até a Praça Rui Barbosa, e dava acesso às chácaras situadas nas margens do Guaíba, na direção da várzea do rio Gravataí. Concluído por Dom Diogo de Souza, que construiu naquele arraial uma casa de veraneio para as autoridades, o Caminho Novo viria a tornar-se

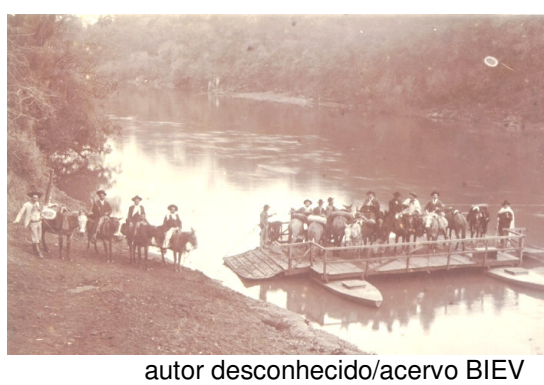

autor desconhecido/acervo BIEV mais tarde a Rua Voluntária da Pátria, estendendo-se até a igreja Nossa Senhora dos Navegantes, quando esta atinge hoje os limites da Avenida Sertório.

Alguns locais nessa época eram escolhidos pela população que desejava banhar-se nas águas do Guaíba. Em algumas praias, de fácil acesso, somente algumas mulheres banhavam-se ali. Havia também os balneários particulares, que, dotados de certa infraestrutura, com trapiche e casinholas, proporcionavam lazer aos primeiros banhistas portoalegrenses que pagassem para usufruir certa privacidade e comodidade.

Na região norte da cidade, em picadas, caminhos e estradas próximos à foz do rio Gravataí, havia um regular transporte de produtos coloniais agrícolas e artesanais, através dos caixeiros viajantes, primeiro em lombo de muares e depois em carretas, principalmente a partir da década de 1830, com a presença dos imigrantes alemães no Vale do Rio do Sinos. Para escoar as carretas com os produtos foi aberta uma estrada para facilitar o transporte até a capital, o que, aliado ao desenvolvimento econômico das colônias alemães, agilizou a circulação de mercadorias entre a capital e as regiões do Vale dos Sinos e Caí. Os produtos começam a chegar a Porto Alegre também através da navegação interior pelos rios Sinos, Caí e Jacuí, em lanchões e barcos a vapor. Nesse período não havia um cais propriamente dito, eram as docas, que possuíam infra-estrutura e depósitos em madeira.

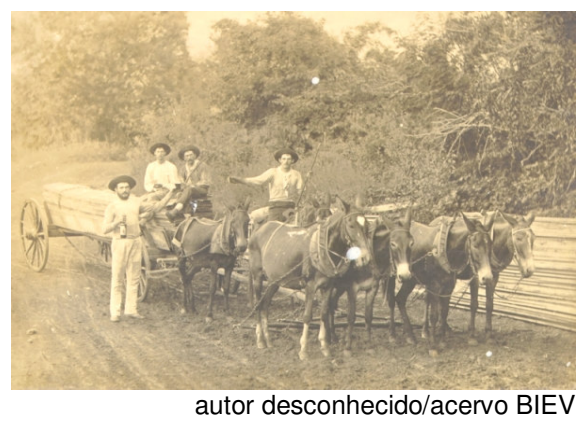

Navegantes e os tempos da guerra dos farrapos Contam alguns historiadores que o período da Revolução Farroupilha (1835-45) foi crucial para o crescimento da importância desta área na vida urbana portoalegrense uma vez que a

\footnotetext{
${ }^{7}$ TERRA, Eloy. As ruas de Porto Alegre. Porto Alegre: AGE, 2002. p.180.
} 
cidade de Porto Alegre, sitiada inúmeras vezes pelas tropas revolucionárias, espremida contra seus muros de defesa continuava se expandido, deslocando sua ocupação para a região norte, na direção das colônias.

Alem disto, durante a revolução dos farrapos, com as barreiras estaduais, o mercado interno rio-grandense toma outro impulso, fazendo com que a comunidade urbana de Porto Alegre, então sede do governo regional, dirija seus olhos para o Caminho Novo na busca de espaço para comportar a expansão de sua $u r b e^{8}$.

Muitos são os cronistas e historiadores que apontam para o grande crescimento comercial desta região da cidade nas décadas subseqüentes à Revolução Farroupilha. As fotografias de acervo nos revelam, neste período, a Rua Voluntários da Pátria, no seu trecho próximo ao centro da cidade, como uma área constituída de grande quantidade e variedade de comércio e lazer, comportando lojas de diversas especialidades, hotéis, casas de espetáculos e cinema 9 .

Remontado alguns relatos historiográficos, apontase para a expressiva circulação de matérias-primas e movimentação econômica no bairro Navegante oriunda da ação empreendedora dos descendentes dos colonos alemães. Esta segunda geração de imigrantes de posse de um saberfazer artesanal dos mais ricos, transfere-se para Porto Alegre, aumentando a comunidade local e diversificando sua paisagem urbana. Com este deslocamento vemos surgir no bairro Navegantes inúmeras profissões urbanas tais como carpinteiros, marceneiros, tintureiros, chapeleiros, tecelões, alfaiates, sapateiros, torneiros, ferreiros, comerciantes, entre outros $^{10}$.

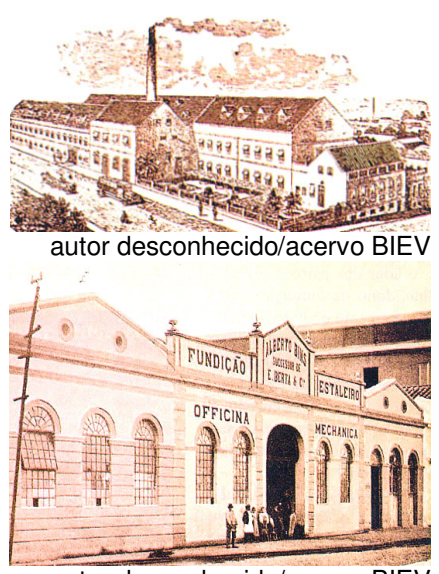

autor desconhecido/acervo BIEV
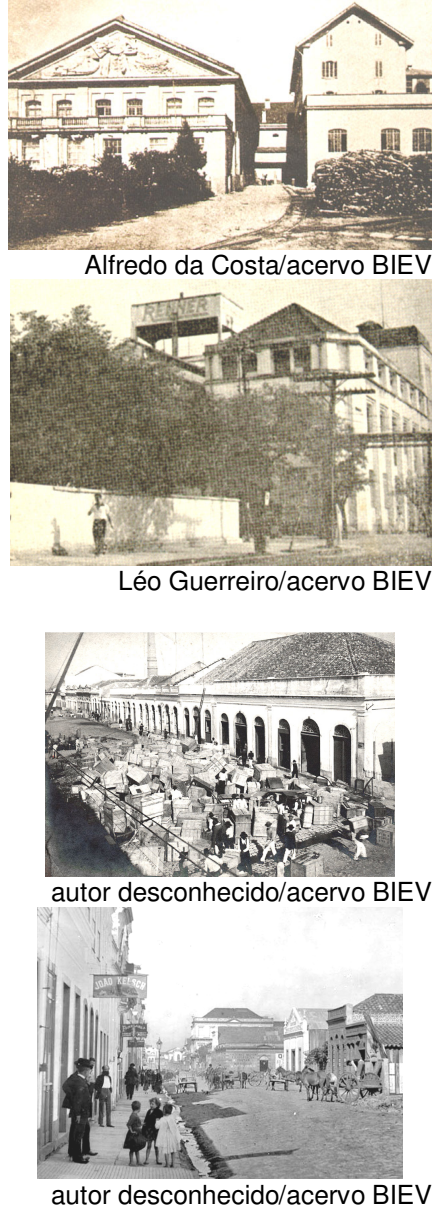

\footnotetext{
${ }^{8}$ MACEDO, Francisco Riopardense. Porto Alegre: origem e crescimento. Porto Alegre: Sulina, 1969.

${ }^{9}$ Diferente de outras ruas, aqui os sobrados estão relacionados à atividades comerciais, pois serviam de residência aos proprietários dos estabelecimentos, depósito, e em alguns casos a funcionários de confiança. (FRANCO, Sérgio da Costa. Gente e espaços de Porto Alegre. Porto Alegre: Ed.Universidade/UFRGS, 2000.)

${ }^{10}$ Segundo alguns historiadores as fases da indústria, verificadas através das políticas sociais, refletiram os momentos de retração e impulso da economia. Foi importante, o período da Guerra dos Farrapos, para a
} 
Tem início, nesta parte da cidade, as empresas artesanais familiares e as fabriquetas, algumas especializando-se e consolidando-se, originando várias pequenas e médias fábricas na região do entorno das docas - fábricas de detergentes, velas, cola, óleos vegetais, fumo, beneficiamento de couro, tecelagens, cervejarias, funilarias, serralherias, metalúrgicas, agroindústrias das mais diversas.

A partir de fins do século XIX e início do XX, com a implantação da estrada de ferro até São Leopoldo, Novo Hamburgo e, posteriormente, Caxias do Sul, o que era um arraial começa a se transformar rapidamente em bairro fabril e operário, expandindo-se por uma série de quadras ao longo das ruas paralelas e perpendiculares, da Rua Voluntários da Pátria até Avenida Sertório. Observa-se que os aterros que a construção de uma tal infraestrutura demandou para a instalação do progresso industrial em Porto Alegre, inclusive com a implementação da estrada-de-ferro ligando a capital as outras cidades do interior, afastavam o Lago Guaíba e suas ilhas da vista dos habitantes do Navegantes.

$\mathrm{Na}$ indústria teuto-brasileira local, o sistema de trabalho dos industriais trazia as características da família patriarcal para dentro da empresa, com hierarquização das tarefas segundo o gênero e a etnia. A indústria era o ponto de encontro da família e comunidade, o patrão a figura do grande pai, como A.J. Renner ou Rubem Berta. Uma política social avançada para a época era oferecida aos trabalhadores, fazendo da empresa a grande concorrente do movimento sindical, devido a variedade de benefícios implantados $^{11} \mathrm{em}$ algumas delas. Segundo apontam os relatos, grande parte das moradias operárias do bairro foram iniciativa das próprias indústrias, através de construção ou de empréstimos aos seus funcionários ${ }^{12}$, além de outros benefícios que se estendiam também para a comunidade local, como o estádio do Renner Futebol Clube, a Igreja Evangélica, escolas e centro de saúde ${ }^{13}$.

\footnotetext{
incipiente indústria gaúcha abastecer o mercado gaúcho, e depois, a crise de 1929, que reduziu as importações, cresceu a indústria nacional, para atender às demandas do mercado interno brasileiro e até internacional. A respeito ver REICHEL, Op. Cit., p.190.

${ }^{11}$ FORTES Alexandre, Industrialização, paternalismo e política: As empresas teuto-brasileiras em Porto Alegre. http://www.duke.edu/web/las/council/fortes.html

${ }^{12}$ FORTES, idem.

${ }^{13}$ REICHEL, Heloisa J.(coord) et al. Vida e trabalho num bairro fabril: depoimentos. In: VIZENTINI, Paulo Gilberto Fagundes et al. Anos 90 - Revista do Curso de Pós-graduação em História, n.2. Porto Alegre:

Ed.Universidade, 1994, p.193.
} 
Avançando no tempo, chega-se as primeiras décadas do séc. XX. Em especial, para o bairro Navegantes, a década de 1930 coincide com início da “época de ouro" do rádio, onde estrelas da música popular brasileira e dramaturgia apresentavam-se ao vivo, tocando e cantando, ou encenando as novelas com os efeitos da sonoplastia direta. Transformados em celebridades no meio artístico pela propagação do rádio, os cantores e atores protagonizam também os produtos dos anunciantes e patrocinadores dos programas do rádio. Comerciais são produzidos, cantados ou dramatizados, anunciando uma grande variedade de produtos, e refletindo os valores da sociedade nesse período consumo, diversificação industrial, e a propaganda ideológica do
Estado Novo, no
governo do
presidente Vargas.
Passada uma década, esta região de Porto Alegre especialmente afetada por uma grande catástrofe que trará um outro perfil para a vida
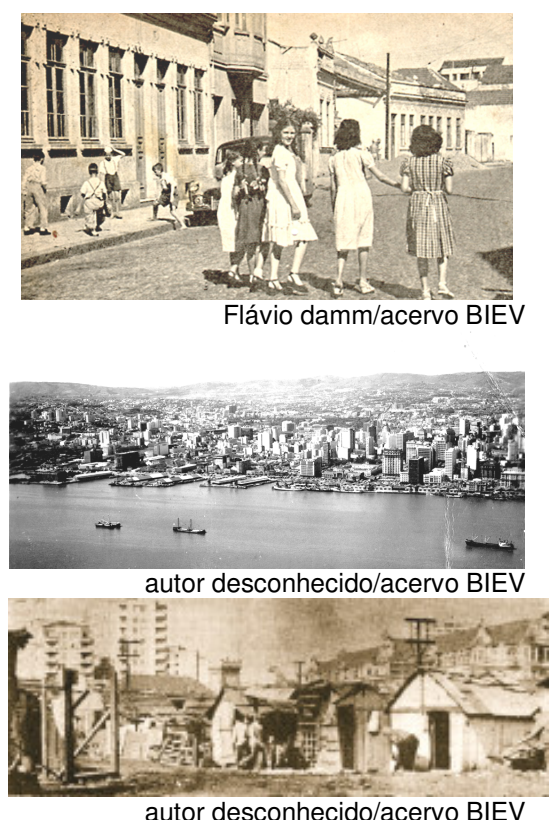

autor desconhecido/acervo BIEV (j)) - Alô Brasil: esta é a PR8, Rádio Nacional do Rio de Janeiro.

E com vocês mais um capítulo de 'O direito de nascer':<smiles>[c]1ccc[cH-]1</smiles>

Estou feliz com meu amor. O Estado Novo veio para nos orientar No Brasil não falta nada, mas precisa trabalhar. Tem café, petróleo e ouro, ninguém pode duvidar... S S

Melhoral, Melhoral, é melhor e não faz mal... J

S. Chop da Brahma é o primeiro que acabam de fazer...

(8) Amigo ouvinte aqui quem fala é o Repórter Esso - testemunha ocular da história...

- Que roupa limpa, branquinha, brancura Rinso minha roupa tem. S

- Mas que beleza, vizinha, com Rinso eu vou lavar também! J

Fonte: Memória BASF/acervo BIEV 1941, o bairro Navegantes foi quase totalmente invadido pelas águas. Tal situação demonstrou a solidariedade através das redes de vizinhança e de trabalho da região, que auxiliou no salvamento do patrimônio industrial atingido pelas águas, mas privilegiou, principalmente, o residencial, revelando o pertencimento de seus habitantes e a comunidade ali estabelecida ${ }^{14}$.

Entretanto, sobretudo após a $2^{\circ}$ Guerra Mundial, com o incremento das rodovias e da migração interna da população de outras cidades do estado para trabalhar na indústria 
local, o aumento populacional contribui para a escassez de moradias na cidade de Porto

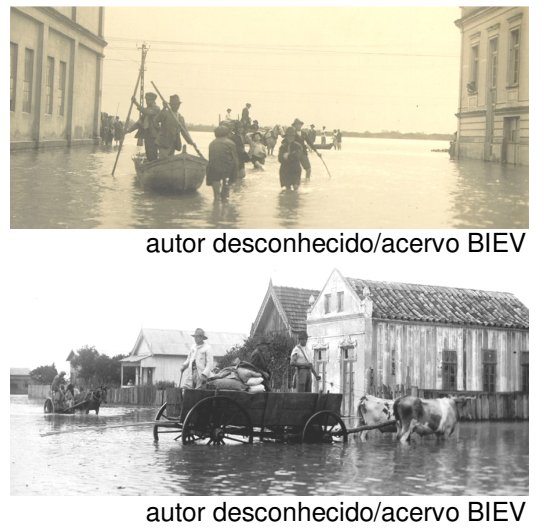

Alegre e no bairro Navegantes. A partir de 1950 outros bairros surgirão em decorrência da expansão da área urbana, através das políticas de habitação e bem estar social, no âmbito do Estado, como o BNH, e nas iniciativas de municipais, como o $1^{\circ}$ Plano Diretor de Porto Alegre, em 1959, que passam a organizar a cidade em regiões conforme suas atividades, perdendo, desde aí o bairro seu perfil característico de arrabalde com vocação operária e fabril.

A especulação imobiliária passa a lotear as áreas entre os arraiais e bairros, em geral ocupadas por moradias irregulares, por suas difíceis condições topográficas, neste caso úmidas. Estas áreas passaram a abrigar loteamentos em quadras do entorno da avenida Presidente Roosevelt, onde hoje estão os bairros vizinhos São João, Floresta e São Geraldo, como o loteamento da Companhia Territorial Porto-Alegrense, que passou a lotear vastas áreas de periferia, com arruamento e alguma urbanização. Afetados direta ou indiretamente por uma série de fatores, e sob a ótica desenvolvimentista do presidente Juscelino Kubistcheck, grande parte das fabricas ascendem à condição de indústrias sendo deslocadas para outros locais da cidade, na busca de área maiores, em direção mais ainda a Norte. A população trabalhadora e grandes parcelas das classes mais populares passam a ocupar as regiões mais periféricas, espaços planejados ou irregulares, como os bairros adjacentes, municípios vizinhos, ou a fronteira norte dos limites municipais. O bairro Navegantes, contextualizado na Porto Alegre que planeja espacialmente suas funções comercial, residencial, industrial, de lazer - a paisagem fabril, operária e familiar transforma-se em simplesmente industrial, acompanhando as transformações no padrão da urbanização das grandes e modernas cidades.

\section{Os bons tempos de Navegantes}

Durante incursão em campo, numa terça-feira, encontrei com Guilherme, arquiteto de 29 anos, na avenida Brasil, onde mora:

Da gurizada aqui da vizinhança só sobrou eu e mais dois aí na banda. Tem o Edu e o Claudião, que foram pro São Geraldo. Eu sei porque é pertinho, a gente ainda se cruza por aí, ou sai junto. Mesmo sem combinar eu canso de encontrar eles ali no Barbatana (Rua Dr. Timótio, bairro Floresta). Tu conhece? É tri porque tem snooker e não é boteco. E ali é fechado também. Aqui pertinho de casa tem um bar

\footnotetext{
${ }^{14}$ A esse respeito ver os relatos de moradores e trabalhadores em FORTES, Alexandre; op cit.
} 
com snooker. Mas é brabo, aquele monte de pinguço, quando não chega umas pintas meio barra pesada. Ah, sei lá. Não dá pra ficar forçando, né.

Com 46 anos, o desenhista Sérgio, durante nossa conversa informal na avenida Presidente Roosevelt, comenta:

A maioria do pessoal, assim que deu, comprou apartamento ou construiu mais pra lá. Uns foram junto com as firmas, ali pra Zona Norte, Canoas, Alvorada. Eu, quando casei fui morar no Sarandi. O Rubens, meu colega desde o Parobé, quando casou, foi morar ali pertinho do Cristo Redentor. Quando se separou foi pra Canoas. Eu e o Rubens, a gente até hoje é colega. Com a correria que a gente tem, que é bom, nem penso em me aposentar. Como será que vai ser quando eu parar?

Após esse período de desocupação de parte das fabricas, das firmas de comércio e residências, o bairro Navegantes inicia, assim, uma outra forma de ocupação, fruto da economia e da urbanização, que se refletem nas formas de habitar e produzir o espaço. Hoje os usos mais diversos foram adaptados, nas lacunas deixadas pelos depósitos, armazéns, fábricas, comércio e moradias que ali haviam.

Assim é que encontram-se na paisagem atual do bairro imensos prédios de antigos depósitos de

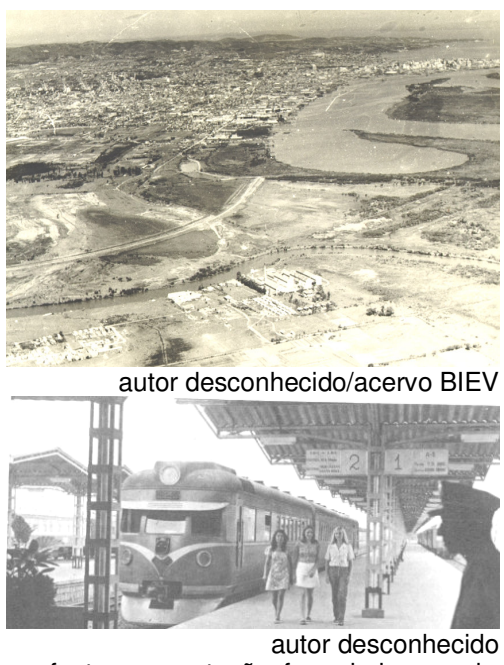
fonte:www.estaçõesferroviarias.com.br

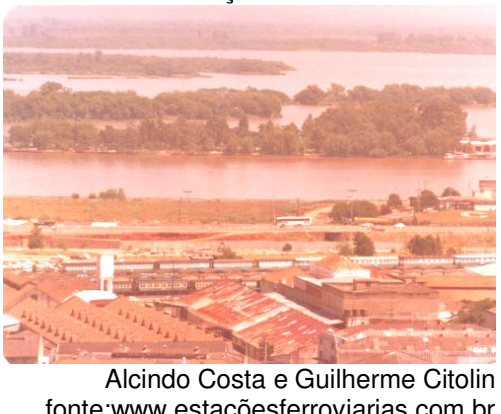
produtos ocupados por galpões de reciclagem, escola de samba e grupos de teatro; indústrias e fábricas em funcionamento, artesanais, pequenas, médias, algumas antigas outras com início recente de suas atividades; os pequenos conjuntos habitacionais para o operariado fabril e industrial, casas, sobrados ou edifícios, em boa parte habitações subalugadas, fazem vizinhança com vilas irregulares ou antigos sobrados, que, abandonados, foram ocupados por invasão ou transformados em pensionatos, hotéis, motéis, redutos de prostituição dos mais diversos, em funcionamento durante vinte e quatro horas, ou a partir do cair da noite ${ }^{15}$; casas noturnas e igrejas evangélicas ocupam sobrados e depósitos; diversificado comércio varejista e atacadista, formal e informal.

\footnotetext{
${ }^{15}$ Em uma busca pelo site "Google" de buscas na Internet, ao digitar o nome de algumas ruas do bairro Navegantes, entre outros itens relacionados a sexo, um dos itens da pesquisa é o Guia Mundial de Turismo Sexual, com os locais de encontros localizados em grande parte nestas ruas.
} 
Na década de 1970 é pavimentada a rodovia BR16 e construída a rodovia Porto Alegre-Osório, a free way. É elaborado o $2^{\circ}$ Plano Diretor do município, cuja estrutura de ocupação privilegiou as perimetrais, ao invés das tradicionais radiais. Foram sendo preenchidas as lacunas da expansão urbana de Porto Alegre, entre a zona central e os núcleos de povoamento, e consolidam-se os bairros da zona norte e a Região Metropolitana de Porto Alegre.

Numa caminhada pelo bairro, num silencioso final de semana, conversei com Cláudio, que é técnico de som e músico, e mora na Rua Hoffmann, sobre a os traços do abandono e da decadência desta área de Navegantes:

Aqui é tranquiilo pra ensaiar porque praticamente só tem esses prédios aí, tudo indústria, depósito, e muito prédio abandonado. E o que tem de material bom, de madeira, plástico, fibra, até móvel bom eu já vi. Mas não é sempre que eu tenho tempo pra voltar e levar pra casa. Bah, dá uma pena quando eu vejo e não posso pegar. Agora, pra chegar ultimamente aqui tá um problema. Tá, antes era menos, mas agora... A gente chega aqui na porta e é essa nojeira na calçada, esse monte de camisinha. E quando tu não tem que carregar as tralhas com as "prosti" fazendo o serviço, ali mesmo no carro, estacionado aqui do ladinho. É um saco, porque fica todo mundo errado. Quando eles se importam com a gente ali trabalhando, tem uns que ainda ficam putos com a gente.

Com 42 anos, microempresário de uma cervejaria artesanal na avenida Brasil,

Mário avalia, sob um uma manhã ensolarada de sábado, as transformações na tradição de saberes e fazeres industriais que antes eram a principal marca do antigo bairro Navegantes, como é o caso da presença, ainda hoje da cervejaria Brahma cujo prédio da antiga fabrica transformou-se num shopping center (Shopping Total):

Por incrível que pareça, eu acho que foi por causa da moda do Dado Bier, esse negócio de cervejaria artesanal tá dando certo. Até agora ganhei muito mais cliente do que perdi. Não tenho o que reclamar. E o bom é que não tá precisando aumentar o espaço aqui pra produzir mais. Não sei até quando também. Eu também não quero correr risco. E se de uma hora pra outra todo mundo resolve beber cachaça?! Ou então não beber mais? Não tem essas campanhas contra o cigarro? Eles nem podem anunciar mais. Daqui a pouco começa com o álcool. Tu já pensou? E o pior que nem é esse o problema, se tem drogado é por outra razão, desemprego, família, educação.

Tratam-se de impressões dos comerciantes que trabalham no bairro Navegantes, nas suas imediações com a área central de Porto Alegre, e que são marcadas pela comparação com a paisagem do antigo bairro ou de outros bairros em relação a está região do bairro Navegantes em função do deslocamento de suas trajetórias sociais na cidade.

Em outra ocasião, percorrendo a rua Ramiro Barcelos, próximo à Avenida Farrapos, numa movimentado fim de tarde de uma dia da semana, encontrei-me com Ana, 39 anos, auxiliar de escritório, cujo local de trabalho fica nos arredores deste entroncamento. Novamente são as imagens da decadência e da ruína moral aquelas que são evocadas para descrever a paisagem local: 
Quando eu trabalhava ali na Dom Pedro (Rua Dom Pedro II), eu esquecia quando tinha que ir pro Centro, e às vezes pegava um ônibus que dá uma volta por dentro ali na Presidente Roosevelt. Eu já vi travesti todinho nu ali na esquina, na frente daquela loja de máquina de costuras, sabe? Não era nem de noite ainda. E o ônibus na esquina, esperando pra entrar no corredor, parado ali na esquina, todo mundo pasmo com aquilo. O motorista e o cobrador eu nem lembro. Devem estar carecas de ver cada coisa. Se a gente vê, imagina eles. Numa hora dessas já é só boteco e inferninho .

Entretanto, ao transitar por esta região do bairro Navegantes, além da agitação dos carrinhos de papeleiros, muitos deles pertencentes a vila de invasão que segue ao longo de parte da Av. Castelo Branco, percebo a presença de inúmeras firmas de representação comercial em funcionamento. Sem dúvida, firmas situadas em prédios antigos, quase galpões, reabilitados para esta função provavelmente pelo atrativo do baixo aluguel, mas mais distantes umas das outras do que já foram em outrora, cercadas por vários prédios desocupados e alguns transformados em quase cortiços. Apesar dos guardas à porta das firmas, pode-se observar a pouca presença, ou a quase inexistência de grades e cercas elétricas protegendo os edifícios e as poucas casas ainda habitadas. O contraste desta paisagem urbana com as ruas de bairros de camadas médias e altas de Porto Alegre, tais como Bonfim, Cidade Baixa, Jardim Botânico, Bela Vista e Montserrat nos faz pensar num bairro cuja comunidade local desenvolveu uma maior tolerância a diversidade de estilos e visões de mundo de seus freqüentadores.

Nas manhãs e durante os fins de semanas, nas amplas ruas que cortam a Rua Voluntários da Pátria em direção a Av. Presidente Roosevelt, podemos encontrar ainda alguns vizinhos conversando no portão de casa ou na calçada. Ao longo da semana sua presença é marcada pelo trajeto dos moradores em direção ao trabalho ou fazendo caminhadas, sendo que nos fins de tarde é a presença de crianças brincando de pegar e de esconder, mais para dentro do bairro, ou em alguma rua sem saída para a Rua Voluntários, o que chama a atenção.

A experimentação com uma etnografia sonora nesta região do bairro Navegantes permitiu, entretanto, a descoberta de uma intensa vida urbana por detrás dos muros das residências e das firmas. Uma paisagem sonora rica e intensa composta da descontinuidade dos sons das máquinas em funcionamento, nas firmas espalhadas entre os muitos prédios do lugar, nos deslocamento de trabalho pelas paradas, terminais de fim de linha ônibus e estação do Trensurb; as vozes das crianças na rua, intercaladas com, ou sob um segundo plano do ruído de alguma avenida movimentada, como a Avenida Farrapos, a Avenida Presidente Roosevelt e a Rua Voluntários, de onde sobressaem, ao longe, o ruído potente do motor de algum ônibus ou caminhão. Em algumas das ruas mais próximas à rodoviária, sons mais discretos são mais imaginados do que necessariamente ouvidos: os 
convites das prostitutas oferecendo seus serviços aos passantes, em geral trabalhadores em divertido trajeto de retorno à casa após mais um dia de trabalho na obra, fábrica ou oficina. $\mathrm{Na}$ região, onde mais se concentram os restos dos antigos sobrados e dos depósitos das velhas fábricas, também se percebe o desafino dos conjuntos musicais de alguma religião evangélica e, desde longe, a entonação amplificada do pastor parece anunciar algo terrível, mesmo sem compreender suas palavras.

\section{Com vistas a uma conclusão}

Como foi sugerido neste ensaio, o bairro Navegantes estendeu sua orla para atender às demandas de circulação, como qualquer outra grande cidade ou metrópole. Rompendo com sua antiga tradição de abrigar o processo migratório de famílias oriundas da área da colônia alemã, oriunda da região do Vale dos Sinos, permitindo seu processo de enraizamento na capital, o bairro Navegantes acabou transformando-se apenas em área de circulação entre outras ruas que servem de passagem a outros bairros vizinhos. Seccionada pela Av. Castelo Branco que se irá transformar, logo, após, na free-way, estrada de acesso as praias do litoral norte rodovia e os trilhos do trem metropolitano, Trensurb, o desenho do atual bairro Navegantes acabou por contribuir direta e indiretamente para uma outra espacialização da cidade. Os diferentes modelos de desenvolvimento da indústria nacional e o planejamento municipal, a médio e longo prazo, tiveram seus reflexos numa configuração local única na cidade: o bairro Navegantes, com suas residências familiares dividindo o espaço com os prédios das indústrias.

Segundo Louis Wirth ${ }^{16}$, muitas vezes para suportar o aumento constante da densidade uma dada área urbana tende a produzir diferenciação e espacialização, uma vez

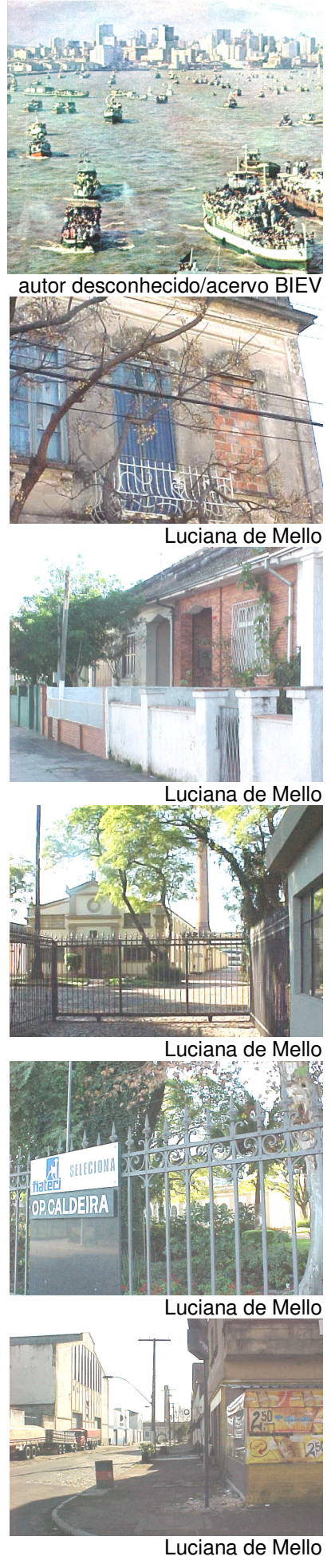

${ }^{16}$ WIRTH, Louis. O urbanismo como modo de vida. In: Velho, Otávio Guilherme. O fenômeno urbano. Rio de Janeiro: Ed. Zahar, 1976. p.102. 
que densidade, pois, reforça o efeito que os números exercem sobre a diversificação dos homens e de suas atividades.

Neste sentido, pode-se pensar que a vida urbana que hoje se pode localizar no bairro Navegantes resulta das apropriações que seus moradores e os poderes públicos municipais dele fizeram ao longo do tempo. Da mesma forma que ele traduz o processo de negociação que seus herdeiros urbanos desenvolveram com o processo de transformação das formas de vida social em Porto Alegre, nos dois últimos séculos, numa constante evocação de suas representações como bairro industrial na memória coletiva desta cidade.

\section{REFERÊNCIAS}

BACHELARD, Gaston. 1884-1962. A poética do espaço. São Paulo: Martins

Fontes, 1993.

CHION, Michel. Le son. Paris: Natan, 1998.

CORUJA, Antônio Álvares Pereira, 1806-1889. Antigualhas: reminiscências de Porto Alegre. Organização e notas de Sérgio da Costa Franco. 2.ed. Porto Alegre: EU/Porto Alegre, 1996.

ECKERT, Cornelia; ROCHA, Ana Luiza Carvalho da. A memória como espaço fantástico. Iluminuras: Série do Banco de Imagens e Efeitos Visuais, número 02. Porto Alegre: BIEV, PPGAS/UFRGS, 2000.

ECKERT, Cornelia e ROCHA, Ana Luiza Carvalho da. Etnografia de rua: estudo de antropologia urbana. Iluminuras: Série do Banco de Imagens e Efeitos Visuais, número 44. Porto Alegre: BIEV, PPGAS/UFRGS, 2001.

FORTES Alexandre, Industrialização, paternalismo e política: As empresas teutobrasileiras em Porto Alegre. http://www.duke.edu/web/las/council/fortes.html

FRANCO, Sérgio da Costa. Gente e espaços de Porto Alegre. Porto Alegre: Ed.Universidade/UFRGS, 2000.

LAGEMANN, Eugênio. Imigração e industrialização. In: Lando, Aldair Marli et al (org.) RS: imigração e colonização. Porto Alegre: Mercado Aberto, 1996

LOBELLO, Marino. Renner Herrmann 70 anos: nas cores da históra. São Paulo: Prêmio, 1997.

MACEDO, Francisco Riopardense. História de Porto Alegre. 3.ed. Porto Alegre: Ed.Universidade/UFRGS, 1999.

MACEDO, Francisco Riopardense. Porto Alegre: origem e crescimento. Porto Alegre: Sulina, 1969.

OLIVEN, Ruben George. Urbanização e mudança social no Brasil. Petrópolis: Vozes, 1980.

PARK, Robert Ezra. A cidade: sugestões para a investigação do comportamento humano no meio urbano. In: Velho, Otávio Guilherme. O fenômeno urbano. Rio de Janeiro: Ed. Zahar, 1976

PESAVENTO, Sandra Jatahy. Memória Porto Alegre: espaços e vivência. Porto Alegre: Ed.Universidade/UFRGS; Prefeitura Municipal de Porto Alegre, 1991.

PESAVENTO, Sandra Jatahy. O espetáculo da rua. Porto Alegre: Ed.

Universidade / UFRGS

Porto Alegre: biografia de uma cidade. Porto Alegre: Tipografia do Centro, 1940.

REICHEL, Heloisa J.(coord) et al. Vida e trabalho num bairro fabril: depoimentos. In: VIZENTINI, Paulo Gilberto Fagundes et al. Anos 90 - Revista do Curso de Pósgraduação em História, n.2. Porto Alegre: Ed.Universidade, 1994.

SANTOS, Milton. Espaço e método. São Paulo: Nobel, 1985 
SPALDING, Walter (org). Porto Alegre: monografia. São Paulo: Habitat, 1953.

WIRTH, Louis. $O$ urbanismo como modo de vida. In: Velho, Otávio Guilherme. $O$ fenômeno urbano. Rio de Janeiro: Ed. Zahar, 1976 